\title{
Aspectos petrográficos e petrológicos de um gnaisse calciossilicático (meta-rodingito) em alto grau na base da Klippe Carvalhos, Faixa Brasília, borda Sul do Cráton São Francisco, em Minas Gerais
}

\author{
Marco Aurélio Piacentini Pinheiro ${ }^{1,2 *}$ \& Marcos Tadeu de Freitas Suita ${ }^{2}$
}

\begin{abstract}
Resumo Na região Sul do Estado de Minas Gerais, na borda meridional do Orógeno neoproterozóico Tocantins, sul do Cráton São Francisco, ocorrem diversos corpos ultramáficos em meio a metassedimentos oceânicos, turbíditicos e pelágicos a hemipelágicos, metamorfisados em médio a alto grau e posicionados ao longo de falhas de empurrão profundas, associadas a granulitos, retroeclogitos e lentes do embasamento. Dentre estes ultramafitos, de origem controversa e possível natureza ofiolítica, destacam-se os ultramafitos do Morro do Corisco e da Fazenda da Roseta, na região da Liberdade. O ultramafito Fazenda da Roseta é constituído por uma associação de metaespinélio harzburgito, metawebsterito, carbonato serpentinito, metabronzitito pegmatoide e litotipos exóticos gnáissicos, de caráter ultramelanocrático e elevada densidade, que foram objeto do estudo. Essas rochas são caracterizadas por uma variedade textural predominantemente representada por três domínios: granoblástico, simplectítico e poiquiloblástico; constituídos pelas mais variadas proporções modais de clinopiroxênio, granada, hornblenda, plagioclásio, magnetita, ilmenita, espinélio, epídoto, com carbonato e mica branca subordinados, e apatita, como fase acessória. Essas rochas exibem forte enriquecimento em $\mathrm{CaO}$ e empobrecimento em $\mathrm{Na}_{2} \mathrm{O}$ e $\mathrm{SiO}_{2}$, incomuns, quando comparadas com rochas metamáficas e metaultramáficas da região. Em diagramas discriminantes, posicionam-se, nos campos de basaltos toleíticos oceânicos, N-MORB, aos de basaltos de arcos de ilhas (IAT). Os padrões geoquímicos são côncavos para os large-ion lithophile elements (LILE) e sub-horizontalizados para os high-field strength elements (HFES) e ETR pesados (ETRP), em relação à abundância desses elementos em composições de basaltos N-MORB. Quando analisadas em conjunto com as rochas metaultramáficas da região, observam-se possíveis relações parentais com os metawebsterito, meta-harzburgito e metabronzitito, que exibem padrões similares de LILE, com anomalia negativa de $\mathrm{Rb}$, e padrões semelhantes de ETR, com padrões enriquecidos em relação ao condrito e uma forte anomalia negativa de Ce. A partir das considerações litotexturais e geoquímicas, o caráter alóctone dos ultramafitos, retroeclogitos, falhas de empurrão profundas associados e proximidade com serpentinitos, sugere-se que essas rochas foram submetidas a um metassomatismo cálcico primário (rodingitização) e são atribuídas a possíveis membros metarodingíticos, em provável ambiente oceânico, em episódio anterior aos processos de subducção e colisão no cenário de fechamento do Oceano Brasilíades, no panorama de estruturação da Orogênese Brasiliana.
\end{abstract}

Palavras-chave: Klippe Carvalhos; meta-rodingito; Faixa Brasília Sul.

\begin{abstract}
Petrographic and petrologic features of a high-grade calcium-silicate gneiss (metarodingite?) at the base of Carvalhos Klippe, Brasilia Belt, Southern border of the São Francisco Craton, Minas Gerais State. In the southern region of Minas Gerais State, in the southern border of the Neoproterozoic Tocantins Orogen, at São Francisco Craton south, several ultramafic bodies occur among oceanic metassediments, turbiditic and pelagic to hemipelagic, in medium to high-grade metamorphism and positioned along deep thrust faults associated with granulites, retroeclogites, and basement slivers. Among these ultramafic rocks of controversial origin and with a probable ophiolitic nature, the most important are the Morro do Corisco and Fazenda da Roseta, in the Liberdade region. The Fazenda da Roseta ultramafic body is made up by an association of meta-spinel harzburgite, meta-websterite, serpentinite carbonate, pegmatitic metabronzitite, and a garnet clinopyroxenite with a gneissic fabric, a possible meta-rodingite. This lithotype shows high density, ultramelanocratic character, banded granoblastic gneissic texture, which is constituted by mineral associations with varied proportions of garnet, clinopyroxene, epidote, and hornblende as the association of metamorphic peak, and plagioclase, epidote, ilmenite, magnetite, carbonate, which forms incomplete simplectitic reactions around garnet, among hornblende, with apatite and carbonate, the accessory minerals. Chemically, these rocks show a characteristic enrichment in $\mathrm{CaO}$ and major $\mathrm{Na}_{2} \mathrm{O}$ and $\mathrm{SiO}_{2}$ depletion when is compared with meta-mafic and meta-ultramafic rocks of the region. These rocks are positioned on the fields of meta-mafic rocks related to N-MORB and IAT. It has curved upward patterns for large-ion lithophile elements (LILE) and flat patterns for HFES and heavy rare earth elements (HREE), when compared with the abundance of these elements in N-MORB basaltic compositions. When this rock is analyzed together with the meta-ultramafic rocks of the region, it is possible to observe possible parental relations with meta-websterite, meta-harzburgite and meta-bronzitite,
\end{abstract}

${ }^{1}$ Companhia de Pesquisa de Recursos Minerais - CPRM/SGB, Superintendência Regional de Belo Horizonte - SUREG-BH, Belo

Horizonte (MG), Brasil; E-mail: marcoaureliopp@yahoo.com.br

${ }^{2}$ Departamento de Geologia, Escola de Minas, Universidade Federal de Ouro Preto - UFOP, Ouro Preto (MG), Brasil. E-mail:

marcos.suita@uol.com.br

*Autor correspondente 
which show similar patterns of LILE, with negative Rb anomaly, and similar REE patterns, with enriched patterns related to chondrite and a Ce strong negative anomaly. From litho-textural and geochemical considerations together with the aloctone character of the associated ultramafics, retroeclogites and deep thrust faults, it is suggested that this (meta) ultramafic rock is a register of a calcium metassomatism (formation of rodingite), a probable meta-rodingite, in a probable oceanic environment, in a former episode to the process of subduction and collision, attributed to the closing of the Brasilíades Ocean, in a scenario of the Brazilian Orogen formation, synchronous to the formation of structural nappes.

Keywords: Meta-rodingite; Southernmost Brasília belt; Klippe Carvalhos.

INTRODUÇÃO Rodingitos são rochas de composição calciossilicáticas pobres em álcalis, que foram submetidas a processos metassomáticos de caráter cálcico, relacionados à serpentinização em ambiente oceânico diretamente associado ao posicionamento de corpos ofiolíticos. São ausentes em associações ultramáficas não serpentinizadas e zonas de contatos de alta temperatura, ocorrem de forma localizada e não têm relação com o metamorfismo regional (Coleman 1963, 1977). O processo de liberação de cálcio durante a serpentinização é evidenciado pelo excesso de hidróxido de cálcio contido em fluidos aquosos emitidos de peridotitos parcialmente serpentinizados (Coleman 1963, 1967, 1977, Barnes \& O’Neil 1969, 1972, Frost \& Beard 2007), os quais são atribuídos como responsáveis pela zona de reação (rodingítica) no contato entre as rochas ultramáficas e as encaixantes de naturezas diversas, como gabro, grauvaca, folhelho, basalto e granito (Coleman 1963, 1977, Wares \& Martin 1980).

As mudanças químicas registradas em rodingitos caracteristicamente resultam em empobrecimento em sílica $\left(<45 \% \mathrm{SiO}_{2}\right)$ e enriquecimento em cálcio $(25$ a $30 \% \mathrm{CaO}$ ), com os componentes $\mathrm{CaO}, \mathrm{MgO}, \mathrm{Al}_{2} \mathrm{O}_{3} \mathrm{e}$ $\mathrm{SiO}_{2}$ constituindo tipicamente entre 85 e $92 \%$ da rocha. $\mathrm{O} \mathrm{TiO}_{2}$ exibe valores de até $2 \%$ e o $\mathrm{FeO}$ exibe um caráter suplementar, sem a existência de fases adicionais diante da partição $\mathrm{Fe}^{2+}-\mathrm{Mg}$ e $\mathrm{Fe}^{3+}-\mathrm{Mg}$, que é responsável pela redistribuição desse componente nas fases existentes (Coleman 1963, 1977, Evans et al. 1979).

Os rodingitos, associações de baixo grau metamórfico, são constituídos por hidrogranada (grossularita) como mineral característico, associado a idiocrásio, diopsídio, phehnita, wollastonita, vesuvianita, clorita, espinélio, tremolita, actinolita e titanita, em rochas de composição química apropriada, com calcita compondo, geralmente, a fase acessória (Frost 1975, Coleman 1977). No entanto, a ausência de calcita é atribuída a estados de equilíbrio em processos de desidratação controlado pela temperatura, enquanto sua presença é regida pela fugacidade finita de $\mathrm{CO}_{2}$ (Rice 1983).
A grossularita é, invariavelmente, restrita a processos metassomáticos com fluidos exibindo $\mathrm{X}_{\mathrm{CO} 2}$ inferior a 0,20 , com valores abaixo de $0,10 \mathrm{em}$ temperaturas menores do que $500^{\circ} \mathrm{C}$. As associações que contêm grossularita + clorita e grossularita + espinélio são restritas a ambientes extremamente ricos em fluidos aquosos e a associação diopsídio + calcita + zoisita+ clorita é restrita a fluidos com $\mathrm{X}_{\mathrm{CO} 2}$ inferiores a 0,07 (Rice 1983).

MATERIAIS E MÉTODOS Para a caracterização litotextural, geoquímica e petrogenética dos litotipos em questão, foram selecionados os espécimes mais representativos, levando-se em conta a intensidade dos processos intempéricos na região, buscando-se, desta forma, a obtenção mais fidedigna possível da identidade e da assinatura da rocha primária. Das amostras selecionadas para análises litogeoquímicas, foram confeccionadas seções delgadas e polidas, as quais foram descritas em microscópio óptico Olympus, modelo BX 41 ocular. As fotomicrografias foram obtidas a partir de um adaptador Olympus Universal Infinity System para captura de imagens acopladas ao microscópio, com resolução de 3,2 megapixels.

As amostras selecionadas para litogeoquímica foram preparadas no Laboratório de Preparação de Amostras para Geoquímica e Geocronologia (LOPAG) do Departamento de Geologia da Universidade Federal de Ouro Preto (DEGEO/UFOP), por meio dos processos convencionais de britagem e moagem. A quantificação analítica foi executada no laboratório da AcmeLabs com os elementos maiores e perda ao fogo quantificados em porcentagem e Ni, e Sc, quantificados em ppm, analisados em grupo analítico de referência 4A, via inductively coupled plasma - optical emission spectrometry (ICP-OES). As amostras foram submetidas à fusão por metaborato/tetraborato de Li e digestão via ácido nítrico, com a perda ao fogo, determinada a partir da diferença de massa após aquecimento a $1.000^{\circ} \mathrm{C}$. Os elementos menores e traços, incluindo os elementos terras raras - ETR ( $\mathrm{La}, \mathrm{Ce}, \mathrm{Pr}$, 
Nd, Sm, Eu, Gd, Tb, Dy, Ho, Er, Tm, Yb e Lu) e Ba, $\mathrm{Be}, \mathrm{Co}, \mathrm{Cs}, \mathrm{Ga}, \mathrm{Hf}, \mathrm{Nb}, \mathrm{Rb}, \mathrm{Sn}, \mathrm{Sr}, \mathrm{Ta}, \mathrm{Th}, \mathrm{U}, \mathrm{V}, \mathrm{W}, \mathrm{Zr}$ e $\mathrm{Y}$, foram analisados em grupo analítico de referência 4B, via ICP mass spectrometry (ICP-MS), com digestão por ácido nítrico e fusão por metaborato/tetraborato de Li. No tratamento dos dados de litogeoquímica, foram utilizados os softwares Minpet Geological Software (versão 2.02), desenvolvido por Richard (1995), e Geochemical Toll Kit, em plataforma R, desenvolvido por Janoušek et al. (2006).

\section{CONTEXTO GEOTECTÔNICO No Sudeste} do Brasil, dois panoramas orogênicos principais são associados à aglutinação brasiliana do Gondwana ocidental, os orógenos Tocantins e Mantiqueira (Campos Neto 2000). O Orógeno Tocantins, Província Tocantins (Almeida 1977), representa o registro inicial da estruturação do Gondwana Ocidental, iniciada a 750 M.a. (Pimentel et al. 1999). Essa envolveu a convergência das placas Amazônia e Rio de la Plata contra a Placa São Francisco-Congo e o fechamento do Oceano Brasilides (Alkmim et al. 2001, Dardenne 2000, Pimentel et al. 2000, Trouw et al. 2000, Ribeiro et al. 2003a,b), com registros dos episódios de subducção e colisão (Brito Neves 1999, Campos Neto 2000), em panorama de fechamento do Oceano Goianides, de idade toniana, posicionado a oeste da Placa Sanfranciscana, no Neoproterozoico (Fig 1A), e na sua porção meridional (Fig. 1B), nas faixas Brasília (Almeida 1977, Fuck et al. 1993) e Alto Rio Grande (Hasui \& Oliveira 1982). O cenário é remontado a partir da convergência da Placa Sanfranciscana sob a Paranapanema. O Orógeno, ou Província Mantiqueira (Almeida 1977), representa um sistema orogênico neoproterozoico, que engloba as faixas Araçuaí, Ribeira, Brasília meridional, Dom Feliciano e São Gabriel (Fig. 1B). O cenário compreende uma série de colisões diacrônicas, com a Placa São Francisco - Rio de La Plata, justaposta, que culmina com o fechamento do Oceano Adamastor, um oceano criogeniano gerado às custas da quebra do supercontinente Rodínia. A porção sul da Faixa Brasília é caracterizada por uma série de nappes, resultantes da colisão neoproterozoica entre as placas San-Franciscana (margem passiva) e Paranapanema (margem ativa), cujos ambientes são sintetizados a partir das próximas três grandes estruturas (Campos Neto et al. 2007; Fig. 1).
Nappe Socorro-Guaxupé A nappe SocorroGuaxupé é considerada o domínio interno dessa série, constitui-se por unidades granulito-granito-migmatíticas provenientes da raiz do arco magmático (Fig. 1C) e exibe condições de metamorfismo de alto grau, com registro de pico metamórfico em 625 M.a. (Campos Neto \& Caby 1999, 2000).

Nappes Andrelândia $\mathrm{O}$ sistema de nappes Andrelândia (Fig. 1C) está associado ao segmento crustal subductado em alta pressão (Campos Neto \& Caby 2000, Trouw et al. 2000) e é dividido em três nappes principais, sendo, da base para o topo: Andrelândia (Trouw et al. 2000), constituída por uma sucessão de metapelitos, metawackes e uma sequência metapelito-psamítica com valores de pico metamórfico em torno de 600 M.a. (Campos Neto et al. 2007), em condições de $688 \pm 35^{\circ} \mathrm{C}$ e 5,63 $\pm 0,9 \mathrm{Kbar}$ (Motta et al. 2010); a Liberdade (Trouw et al. 2000), constituída por sequência metapelítica-psamítica e gnaisses calciossilicáticos, submetida a condições metamórficas em torno de $648 \pm 23^{\circ} \mathrm{C}$ e 7,41 Kbar (Motta et al. 2010) e posicionada em torno de 611 M.a. (Campos Neto et al. 2007); e a nappe Três Pontas-Varginha e klippens associadas (Serra da Natureza, Aiuruoca, Carvalhos e Pouso Alto; Campos Neto et al. 2007), composta por metapelitos (pelágicos a semipelágicos), submetidos a fácies granulito de alta pressão (Trouw et al. 2000), com valores para o pico metamórfico em torno de $900^{\circ} \mathrm{C}$ e $15 \mathrm{Kbar}$ (Campos Neto \& Caby 1999).

As rochas metamáficas, metaultramáficas e retroeclogitos, de natureza controversa, posicionam-se em meio às unidades desse sistema de nappes, que compõe lentes e boudins, concentradas nos contatos entre as nappes (Trouw 1992, Campos Neto \& Caby 1999, Trouw et al. 2000) e são relacionadas a componentes de associações desmembradas de fracionados toleíticos continentais (Gonçalves \& Figueiredo 1992, Paciullo 1992, Almeida 1992, 1998) ou de ofiolitos (Pinheiro 2008, Pinheiro \& Suita 2008).

Sistema de nappes Carrancas (Trouw et al. 2000) e Lima Duarte (Campos Neto et al. 2004; Fig. 1C) Este compõe a porção externa do Orógeno Brasiliano, está relacionado à margem passiva da placa SanFranciscana (Trouw et al. 2000), apresenta um gradiente metamórfico do tipo barroviano, com padrões metamórficos inversos (Ribeiro et al. 1995, Heilbron et al. 1995) e exibe condições metamórficas em torno 

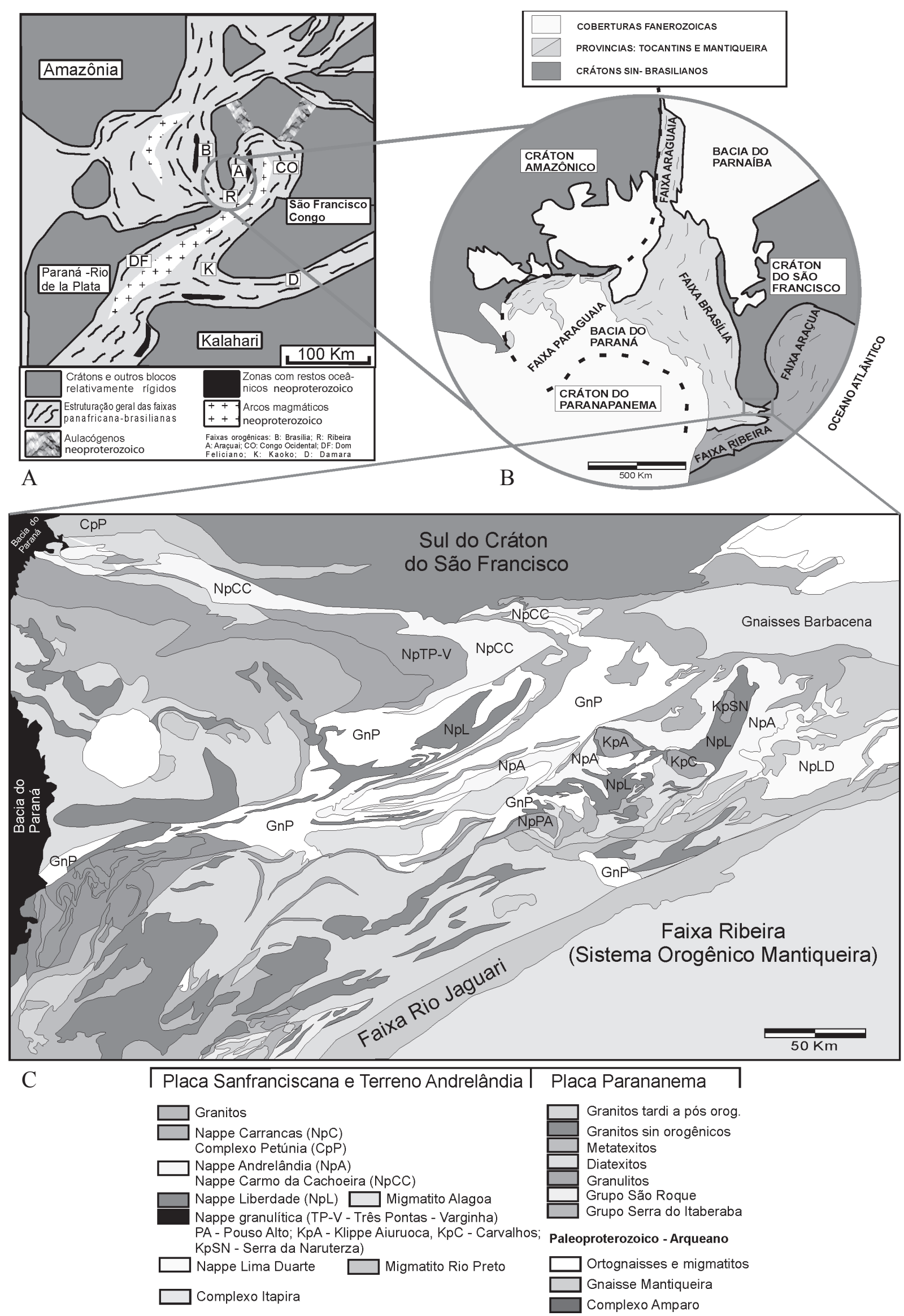

Figura 1 - Figura que localiza as faixas orogênicas e núcleos cratônicos no contexto do: (A) mapa do paleocontinente Gondwana Ocidental (modificado de Brito Neves et al. 1999); (B) destaque para o esboço tectônico do Brasil central (modificado de Almeida et al. 1977); e, (C) simplificação geológica de parte do Orógeno Tocantins meridional (modificado de Campos Neto et al. 2004). 
de 500 a $570^{\circ} \mathrm{C}$ e 7,3 a $7,5 \mathrm{Kbar}$, obtidos em metapelitos. Condições em torno de $950^{\circ} \mathrm{C}$ e $12 \mathrm{Kbar}$ foram determinadas em granulitos máficos da nappe Lima Duarte, e idades em torno de 590 M.a. foram estimadas para o pico metamórfico desse sistema (Campos Neto et al. 2004, 2007). Trouw \& Pankhrust (1993), Ribeiro et al. (1995) e Campos Neto \& Caby (2000) determinaram, a partir de métodos termobarométricos, condições de 12 a $13,5 \mathrm{Kbar}$ e 800 a $900^{\circ} \mathrm{C}$ para o equilíbrio de alto grau. Perrault \& Martignole (1998 apud Heilbron et al. 2003a) determinaram valores de reequilíbrio de 600 a $700^{\circ} \mathrm{C}$ em par de granada-cordierita, com a cordierita associada com granada e sillimanita em leucossomas tardideformação brasiliana, o que indica a descompressão ocorrida após o metamorfismo principal (Heilbron et al. 2003a). Almeida (1998) obteve valores entre 700 e $900^{\circ} \mathrm{C}$ e 12 e 13,5 Kbar de pressão para a formação das associações metaultramáficas posicionadas em meio às unidades da nappe Andrelândia. Dados geocronológicos, obtidos pelo sistema $\mathrm{U}-\mathrm{Pb}$, exibem valores entre $565 \mathrm{Ma}$, para a descompressão gerada após o pico metamórfico, relacionados à evolução da Faixa Brasília e no intervalo de tempo entre 535 e 502 M.a., para as associações metamórficas relacionadas à estruturação da Faixa Ribeira (Heilbron et al. 2003a).

\section{CONTEXTO GEOLÓGICO A klippe Carvalhos,} "uma escama de empurrão que cavalga as rochas do domínio Andrelândia" (Heilbron et al. 2003a), arquitetada durante a Orogênese Brasiliana (Paciullo et al. 2003a) e reestruturada na forma de um braquissinformal pela Orogênese Ribeira (Heilbron et al. 2003a), é constituída de paragnaisses a rutilo, cianita, granada e ortoclásio pertítico, nas mais variadas proporções, e exibe valores de pico metamórfico em torno de $850^{\circ} \mathrm{C}$ e $16 \mathrm{Kbar}$ (Cioffi 2009). Rochas metabásicas boudinadas, encaixadas nos paragnaisses, com paragêneses reliquiares de granada + clinopiroxênio + quartzo \pm plagioclásio, têm simplectitos de hornblenda + plagioclásio em granada e coronas descontínuas de ilmenita. Estas rochas exibem idades em torno de 582,9 $\pm 14,8$ M.a. (método K-Ar), com o pico metamórfico posicionado em torno de $618 \pm 2,2 \mathrm{Ma}(\mathrm{U}-\mathrm{Pb} ;$ ID-TIMS em monazita)

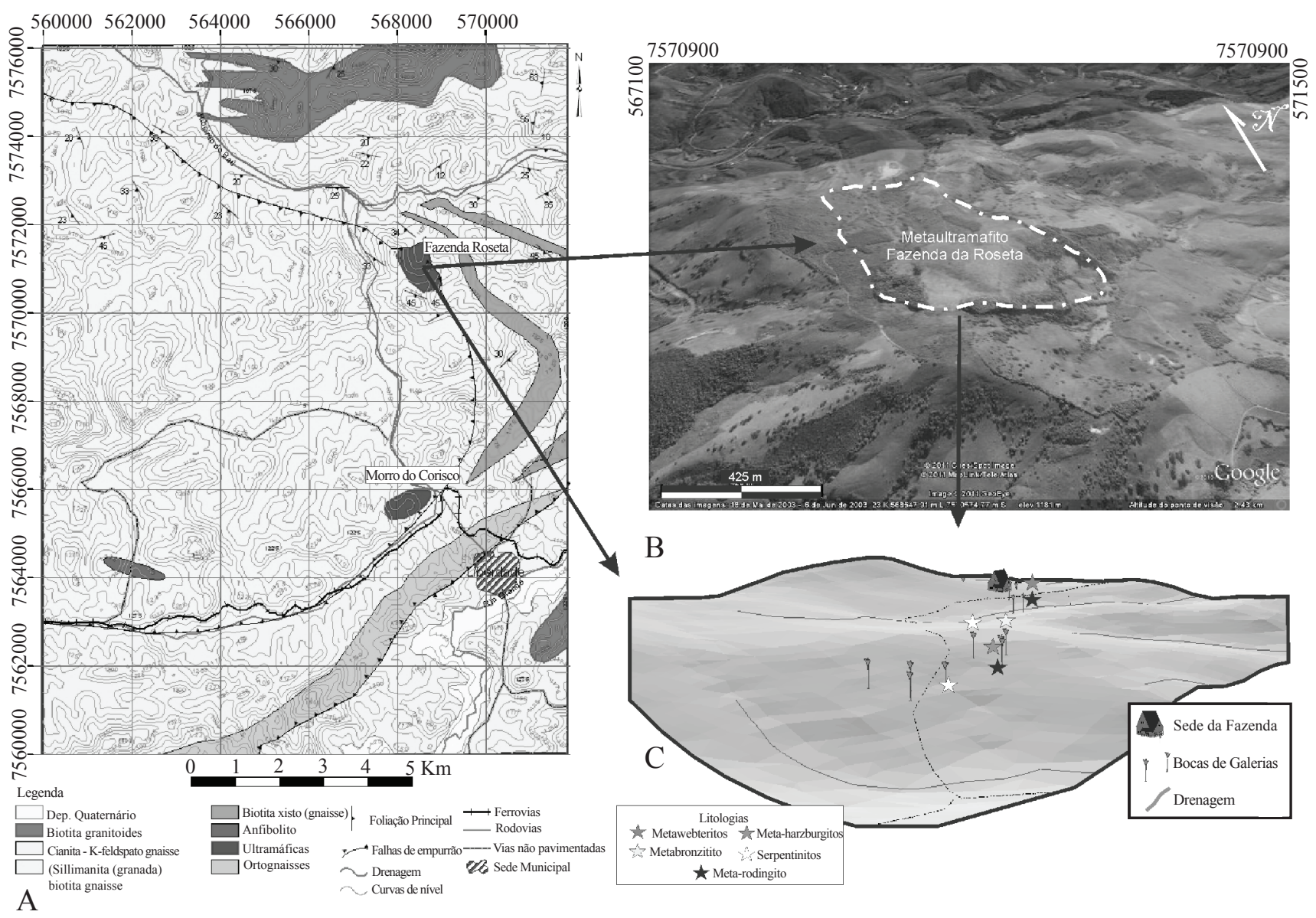

Figura 2 - Figura que mostra: (A) Mapa geológico da porção SE da klippe Carvalhos (extraído de Paciullo et al. 2003b e Heilbron et al. 2003b); (B) delimitação do ultramafito Fazenda da Roseta (a partir de imagem do Google Earth); (C) ocorrência de litotipos ultramáficos e do granada-clinopiroxênio-hornblenda gnaisse com epídoto, sobre MDT de terreno obtido a partir de SRTM, com definição de $30 \times 30 \mathrm{~m}$. 
e valores termobarométricos de $850^{\circ} \mathrm{C}$ e $15 \pm 2 \mathrm{Kbar}$ (Cioffi 2009). Na base dessa unidade tectônica, ocorrem os principais metaultramafitos da região: Fazenda da Roseta; e, Morro do Corisco.

O corpo do Morro do Corisco (Fig. 2A), o ultramafito mais estudado da região (Santos 1972, Silva 1992, Almeida 1992, 1998, Pinheiro 2008, Pinheiro \& Suita 2008), é constituído por serpentinitos maciços com núcleos preservados de meta-harzburgito, metadunito e metaespinélio hornblendito (Almeida 1998, Pinheiro 2008). Os serpentinitos são compostos por lizardita, minerais opacos e espinélio, com traços de clorita, talco, carbonato, além de ortopiroxênio e olivina reliquiares. Possuem bandas de espessuras centi- a decimétricas, de diferentes tonalidades e com pseudomorfos de olivina e/ou ortopiroxênio orientados primariamente, sem correlação com as principais estruturas regionais e que exibem evidências de processos de serpentinização primária (Pinheiro 2008, Pinheiro \& Suita 2008).
O corpo da Fazenda da Roseta (Figs. 2B e C), com aproximadamente $4 \mathrm{~km}^{2}$ de exposição superficial, constitui o maior corpo ultramáfico da região e compreende a associação de, ao menos, cinco litotipos: metaespinélio harzburgito; metawebsterito; carbonato serpentinito; metabronzitito pegmatoide; e, granada-clinopiroxênio-hornblenda gnaisse com epídoto, um ultramafito incomum na região, que é o objeto deste traba1ho. Ocorrem, também, clorita e muscovita xistos nas bordas deste corpo que apresentam relações estruturais complexas e de difícil visualização, pertencentes às unidades da klippe de Carvalhos. Devido à presença de níquel laterítico no ultramafito da Fazenda da Roseta (hoje uma mina paralisada), a área teve, na década de 1950, uma campanha de exploração mineral, tendo sido abertas galerias de pesquisa (Fig. 3A). Estes foram os principais e melhores pontos de amostragem de serpentinitos, meta-harzburgito, metawebsterito e granada clinopiroxenito gnaisse com hornblenda, localizados em áditos destas galerias, em contatos com difícil estabelecimento do contexto estrutural (Figs. 3B e C).
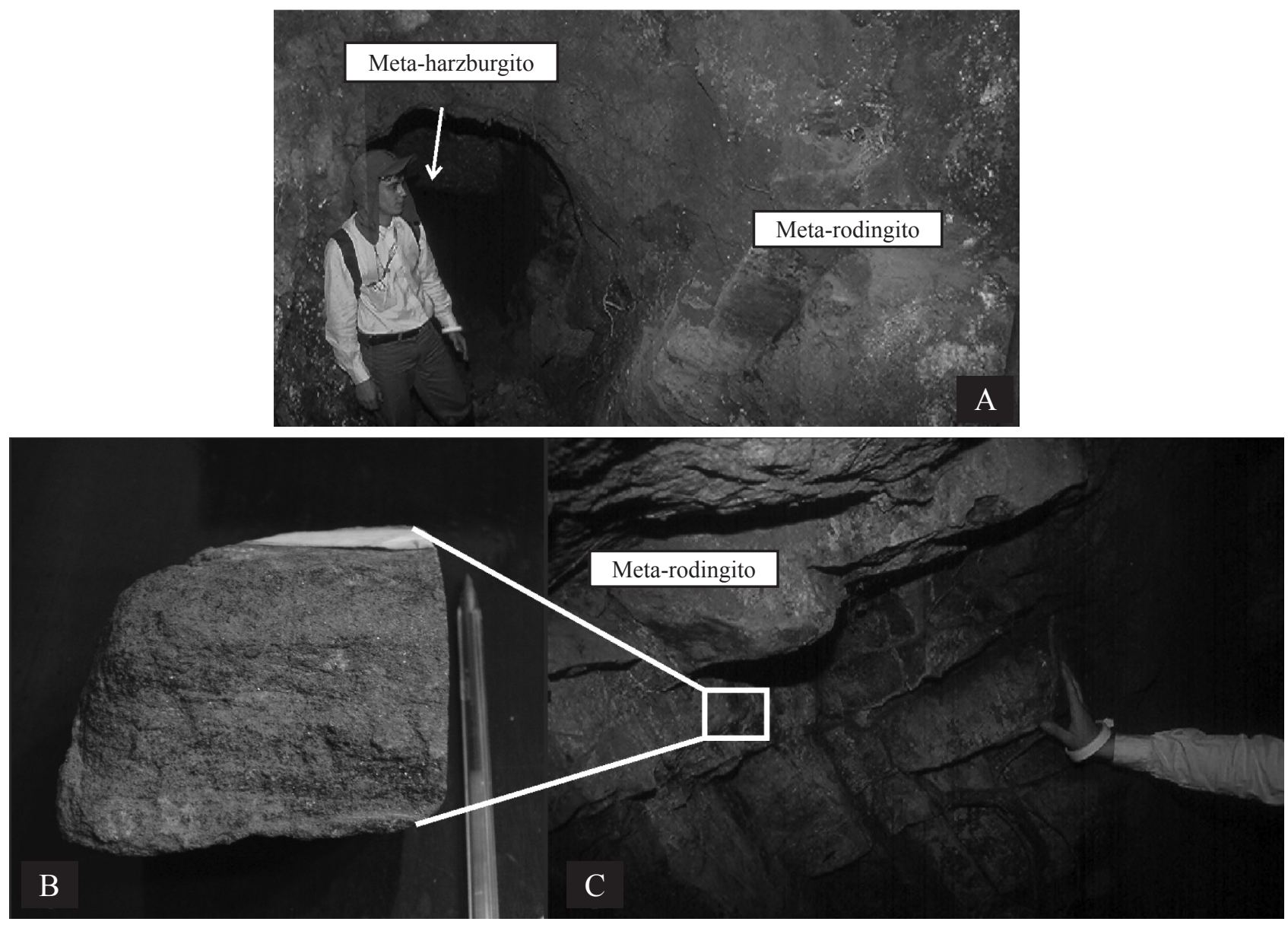

Figura 3 - Fotografias no corpo ultramáfico da Fazenda da Roseta que mostram: (A) ocorrência de metaharzburgito serpentinizado ao fundo de galeria de pesquisa; (B) amostra de rocha ultramelanocrática que exibe bandamento composicional gnáissico milimétrico (meta-rodingito?); (C) Detalhe de afloramento do gnaisse calciossilicático (meta-rodingito) em ádito de galeria. 


\section{ASPECTOS PETROGRÁFICOS DOS GRANADA CLINOPIROXÊNITO GNAISSES}

Macroscopicamente, estes gnaisses de composição calciossilicática apresentam elevada densidade, caráter ultramelanocrático, cores verde escura à negra. Têm solos, característicos, com matizes ocres e, não raro, formam duricrosta. Os litotipos exibem um bandamento composicional irregular, mili- a centimétrico, com arranjo nematoblástico de hornblenda ao longo das bandas. Por microscopia, foram observadas associações litológicas constituídas por clinopiroxênio, ilmenita, magnetita, hornblenda, espinélio, granada, epídoto e plagioclásio como fases essenciais e com carbonato e apatita, como acessórios, distribuídos nas mais variadas proporções modais, o que dificulta a quantificação modal mineral e, consequentemente, sua caracterização petrográfica. Assim, essas associações foram dispostas em dois membros finais: espinélio-clinopiroxênio-hornblenda gnaisse ( $\mathrm{Gn}$-spl); e, granada-clinopiroxênio-hornblenda gnaisse com epídoto (Gn-grd), com membros intermediários comuns e com significativo conteúdo modal de magnetita e ilmenita.

Esses litotipos são constituídos por três domínios texturais: granoblástico (Dg; Figs. 4A e B); poiquiloblástico (Dp; Figs. 4C e D) e simplectítico (Ds; Figs. 4E e F). O domínio Dg é caracterizado por arranjos em mosaico de clinopiroxênio, hornblenda, granada, epídoto e, subordinadamente, espinélio. A trama é equigranular fina à média, com texturas simplectíticas lamelares/globulares de plagioclásio + epídoto (?) + hornblenda ao redor de granada. Ocorrem coroas descontínuas de ilmenita (+ magnetita) nas bordas dessa textura de reação. Não raro, ocorrem horizontes monominerálicos de granada, ou clinopiroxênio, ou epídoto, ou espinélio (s.s.) e/ou opacos, distribuídos de acordo com a compatibilidade química dos diversos membros.

O domínio Dp é caracterizado por grãos de hornblenda, magnetita e ilmenita, em arranjo poiquiloblástico, não raro com espinélio (s.s.), abundantes nos termos com granada subordinada. Os poiquiloblastos tendem a arranjos granoblásticos, mas apresentam-se majoritariamente em grãos xenoblásticos com contatos irregulares, ameboides, em cúspide e interdigitados, e constituem "oikocristais", que envolvem epídoto e clinopiroxênio. Neste domínio, as texturas simplectíticas são menos frequentes.

O domínio Ds exibe um caráter tardio em relação ao Dg e Dp, sendo constituído pelo intercrescimento de plagioclásio + hornblenda + epídoto (?) + ilmenita ao redor de granada (Gn-grd) e próximo a magnetita + ilmenita e clinopiroxênio (Gn-spl). Xenoblastos neoformados de plagioclásio, epídoto, hornblenda e ilmenita, com carbonato subordinado, ocorrem em porções em que essas reações estão mais desenvolvidas.

De modo geral, a hornblenda predomina (mínimo $35 \%$ e máximo de $50 \%$ ), ocorre em trama inequigranular média a grossa (Dp) e fina a média (Dg e Ds), exibe um forte pleocroísmo, em matizes de verde-oliva a azul, com cristais que apresentam maclas, zonamento e estruturas do tipo extinção ondulante. Em muitas seções, ocorrem inclusões de epídoto, clinopiroxênio e ilmenita (Dp). Esta última fase ocorre como diminutos grãos aciculares exsolvidos e orientados paralelamente aos planos de clivagem do anfibólio. No Ds, a hornblenda compõe, quando não em cristais granoblásticos, intercrescimento lamelar, junto a plagioclásio e epídoto (?), ao redor de granada (Gn-grd) próximo à grãos de magnetita e ilmenita. Em algumas seções, ocorrem interdigitações de espinélio e ilmenita a partir de grãos de hornblenda.

O clinopiroxênio constitui cerca de $20 \%$ do membro Gn-grd e em torno de 12\% Gn-spl. Este mineral apresenta-se em grãos granoblásticos, que compõem mosaicos inequigranulares finos. A sua variação modal, junto com a de hornblenda, granada, epídoto e espinélio, principalmente no Dg, caracteriza o bandamento gnáissico. Não raro ocorrem horizontes monominerálicos. Em algumas seções, observou-se clinopiroxênio, possivelmente, reliquiar, próximo a contatos com metawebsterito e meta-harzburgito serpentinizados, onde este mineral forma porfiroclastos precoces que contatam clinopiroxênio recristalizado (poligonal) e granada.

A granada forma granoblastos, constitui arranjos em mosaico, e compõe cerca de $20 \%$ no Gn-grd e aproximadamente 10\% no Gn-spl. Em muitas porções, ocorre em bandas distintas, associada com hornblenda, clinopiroxênio e epídoto $(\mathrm{Dg})$ e clinopiroxênio, opacos e espinélio (Ds). Está ausente no Dp. No Ds, ocorre de modo reliquiar no núcleo das reações simplectíticas entre hornblenda, plagioclásio, epídoto (?) e opacos vermiformes (Figs. 5A e B).

$\mathrm{O}$ epídoto compõe textura inequigranular fina, exibe tom esverdeado, cores de interferência vivas e zoneamento composicional. Em porções do Dg, no Gn-grd, o epídoto ( $>10 \%)$ ocorre em trama intergranular entre granada e clinopiroxênio. Em algumas seções, forma horizontes monominerálicos, discordantes do bandamento gnáissico, com grãos médios a 
grossos, com arranjo em mosaico (vênulas recristalizadas?). No Ds, ocorre intercrescido com plagioclásio + hornblenda + ilmenita, em reações simplectíticas ao redor de granada. É frequente a neoformação de xenoblastos em zonas de maior expressão dessa reação.
No Dp, compõe coronas (quelifita) ao redor de opacos (magnetita + ilmenita), está incluso nessas fases e associa-se ao espinélio, preferencialmente no Gn-spl.

O espinélio (s.s.) forma xenoblastos de cor verde-garrafa e textura inequigranular fina a grossa.

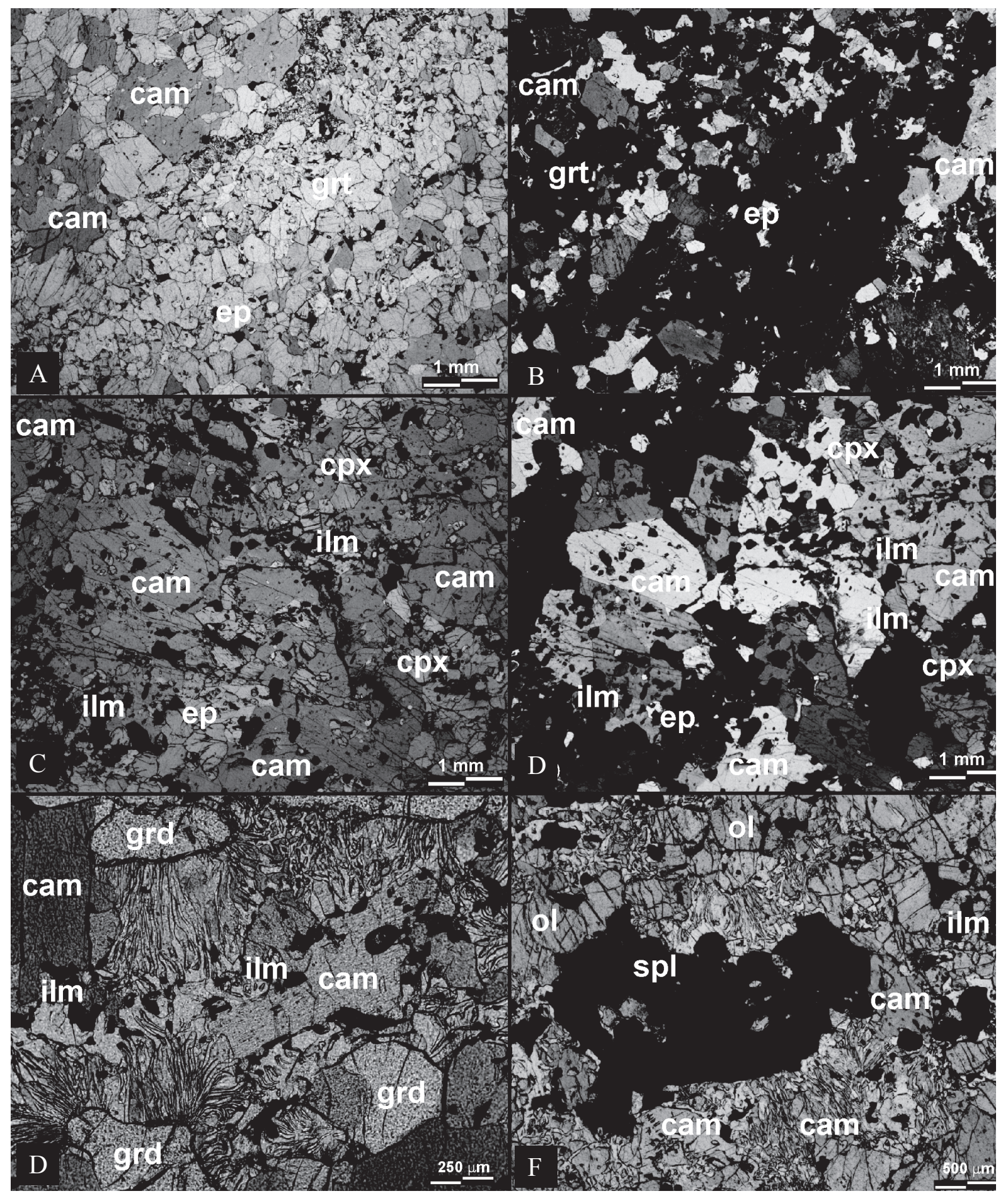

Figura 4 - Fotomicrografias que mostram: (A) e (B) horizonte granatifero com clinoanfibólio, clinopiroxênio e epídoto com textura granoblástica em litotipos Gn-grd e Dg (luz natural, LN, e nicois cruzados, NC, respectivamente); ( $C$ e D) clinoanfibólio poiquiloblástico que constitui o $D p$ ( $L N$ e $N C$, respectivamente); (E) reações simplectíticas ao redor de granada em Gn-grd e Ds (LN); e (F) reações simplectíticas ao redor de clinopiroxênio com espinélio poiquiloblástico em $\mathrm{Gn}$-spl e Ds (LN). As abreviações minerais foram feitas segundo Whitney \& Evans (2010). 
Esta fase associa-se a magnetita e ilmenita, predomina no Ds, é frequente no Dg e subordinada a ausente no Dp (Figs. 5C e D). Em regiões com intensa formação de simplectita e, em litotipos com granada subordinada e opacos abundantes, o espinélio constitui horizontes monominerálicos. Por vezes, observaram-se inclusões de clinopiroxênio, opacos e apatita em espinélio poiquiloblástico.
A magnetita e ilmenita se associam e são mais comuns no Ds, ocorrem em grãos poiquiloblásticos com contatos ameboides, interdigitados e em cúspide, portando inclusões de epídoto, clinopiroxênio, e, subordinadamente, hornblenda e apatita. Comumente, exibem textura quelifítica com epídoto e espinélio posicionados em posições intergranulares. A ilmenita compõe uma coroa descontínua nas margens das

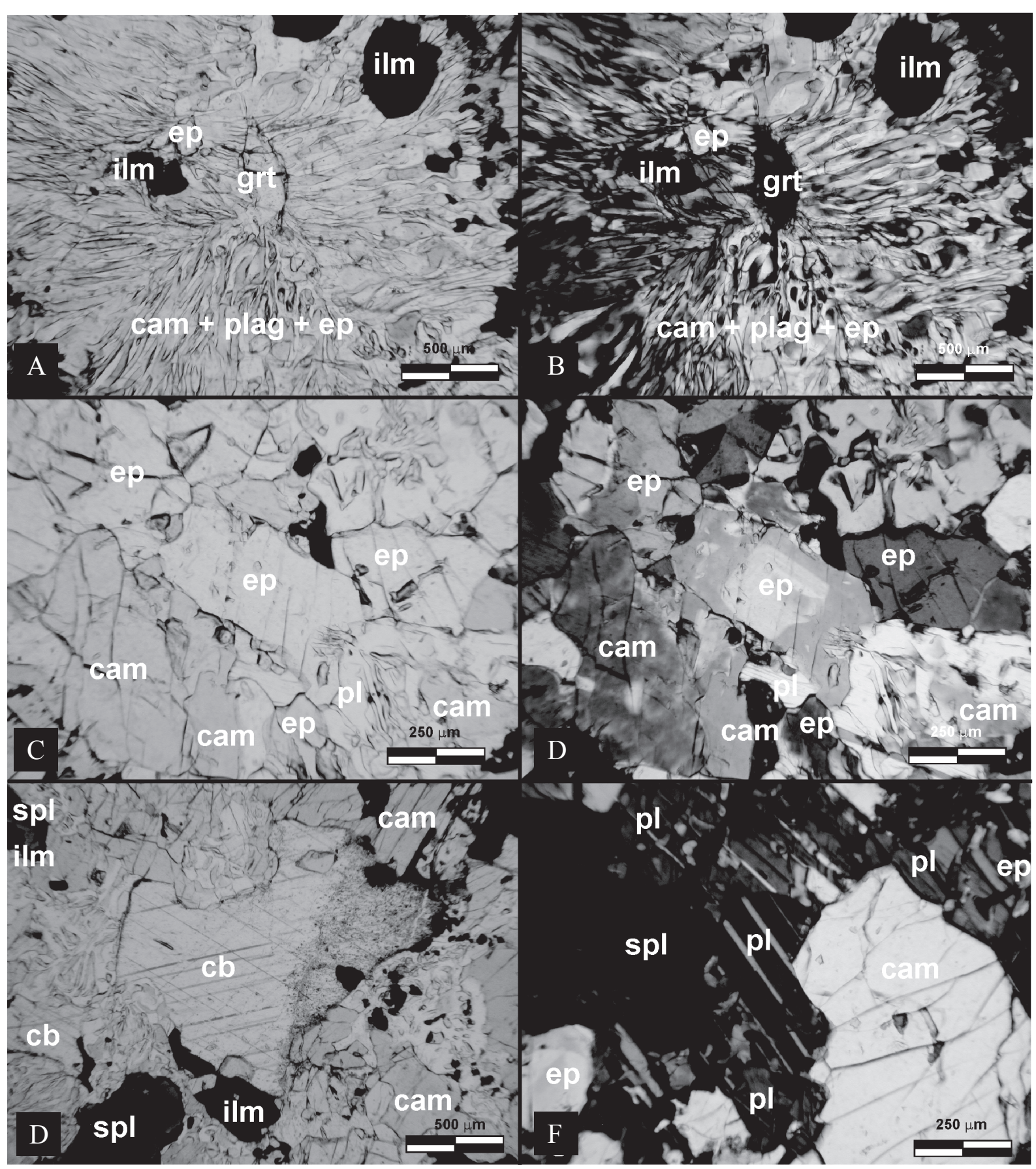

Figura 5 - Fotomicrografias que mostram: (A e B) granada reliquiar em núcleo de reação simplectítica em Gn-grd e Ds (LN e NC, respectivamente); (C e D) epidoto zonado neoformado em Gn-grd no Dg (LN e $N C$, respectivamente); (E) carbonato neoformado em região de reações simplectíticas no $G n-s p l$ e $D s$ (LN); (F) plagioclásio e epídoto neoformados em porções com reações simplectíticas abundantes (NC). Todas as abreviações minerais foram feitas segundo Whitney \& Evans (op. cit.). 
regiões de reações simplectíticas e ocorre de forma globular e lamelar no interior dessas regiões.

O plagioclásio ocorre em grãos vermiformes a granoblásticos neoformados e associa-se a hornblenda, epídoto e ilmenita, restritos nas regiões das reações simplectíticas, ao redor de granada. Ocorre próximo a opacos e espinélio no Ds, e inexiste no Dp. Xenoblastos de plagioclásio com maclas polissintéticas, muitas vezes deformadas e descontínuas, ocorrem em regiões com total consumo de granada $(\mathrm{Dg})$ ou naquelas com intensas reações simplectíticas, junto a carbonato, hornblenda e epídoto neoformados. A moda deste mineral é muito variável, de inexistente até $10 \%$.

A mineralogia acessória é constituída por apatita, carbonato e mica branca. A apatita ocorre em grãos finos, xeno- a subidioblásticos, inclusa no espinélio e, associada a opacos. O carbonato forma xenoblastos finos com contatos interlobados, que formam arranjos granoblásticos no Ds, em zonas com expressivas reações simplectíticas. Associa-se a plagioclásio, epídoto e hornblenda, mais frequente em litotipos com granada menos abundante ( $>10 \%)$. A mica branca é subordinada, em xenoblastos finos, associada ao plagioclásio, sempre nas regiões simplectíticas (Ds).

LITOGEOQUíMICA Por análises litogeoquímicas (que incluíram elementos maiores, menores e traços) de amostras representativas dos litotipos estudados, foram feitas considerações petrogenéticas e suas implicações genético-evolutivas. Os dados (Tab. 1) evidenciam o caráter ultrabásico dos litotipos $\left(\mathrm{SiO}_{2}<45 \%\right)$ e sua afinidade toleítica (Fig. 7A), com olivina normativa. A observação e análise de elementos maiores destes litotipos (Figs. 6A-H), comparados com os de rochas metaultramáficas associadas (Pinheiro 2008) e com as metabásicas de diferentes naturezas (plutônicas e vulcânicas), posicionadas em várias unidades de sequências neoproterozoicas das nappes Andrelândia e Liberdade (atribuídas a membros diferenciados desmembrados; Pinheiro inédito), mostram assinaturas geoquímicas similares e exibem característico empobrecimento em $\mathrm{Na}_{2} \mathrm{O}$ e $\mathrm{SiO}_{2}$. Por fim, há enriquecimento em $\mathrm{Ca}$ nos mesmos, anômalo e sem precedentes para as rochas da região (Figs. 6A, C e D).

$\mathrm{O} \mathrm{MgO}$ foi usado como índice de diferenciação (Figs. 6A-H), e observou-se a possível afinidade parental destes gnaisses calciossilicáticos com outras rochas metaultramáficas associadas. Destaca-se esta rocha como um provável membro ultramáfico derivado (pelos padrões de $\mathrm{MgO}$ versus $\mathrm{Al}_{2} \mathrm{O}_{3}, \mathrm{~K}_{2} \mathrm{O}$, $\mathrm{FeO}^{\mathrm{T}}$ e $\mathrm{CaO}$; Figs. 6B, C, E e H). Estas rochas mostram-se similares químicamente com as metamáficas por agruparem-se em regiões específicas, o que é

Tabela 1 - Análises litoquímicas que apresentam elementos maiores (\%), menores (ppm) e traços (ppm/ppb) de amostras do granada clinopiroxenito gnaisse com hornblenda e de outros (meta)ultramafitos da Fazenda da Roseta

\begin{tabular}{llllllllll}
\hline Amostra & $\mathrm{SiO}_{2}$ & $\mathrm{Al}_{2} \mathrm{O}_{3}$ & $\mathrm{Fe}_{2} \mathrm{O}_{3}$ & $\mathrm{MgO}$ & $\mathrm{CaO}$ & $\mathrm{Na}_{2} \mathrm{O}$ & $\mathrm{K}_{2} \mathrm{O}$ & $\mathrm{TiO}_{2}$ & $\mathrm{P}_{2} \mathrm{O}_{5}$ \\
\hline $149-1$ & 39,27 & 16,2 & 14,5 & 8,94 & 16,48 & 0,32 & 0,08 & 1,32 & 0,1 \\
\hline $149-4-1$ & 33,57 & 17,88 & 18,45 & 10,39 & 14,57 & 0,29 & 0,07 & 2,72 & 0,2 \\
\hline $149-4-2$ & 39,12 & 16,87 & 13,95 & 9,48 & 17,27 & 0,33 & 0,1 & 1,26 & 0,1 \\
\hline Amostra & $\mathrm{MnO}$ & $\mathrm{Cr}_{2} \mathrm{O}_{3}$ & $\mathrm{Ti}$ & $\mathrm{Ni}$ & $\mathrm{P}$ & $L O I(\%)$ & $\mathrm{TOT} / \mathrm{C}(\%)$ & $\mathrm{TOT} / \mathrm{S}(\%)$ & $\mathrm{SUM}(\%)$ \\
\hline $149-1$ & 0,23 & 0,01 & 0,79 & 1.087 & 0,04 & 2,2 & 0,02 & 0,01 & 99,8 \\
\hline $149-4-1$ & 0,31 & 0,01 & 1,63 & 936 & 0,09 & 1,2 & 0,15 & 0,01 & 99,79 \\
\hline $149-4-2$ & 0,24 & 0,01 & 0,76 & 590 & 0,04 & 1 & 0,04 & 0,01 & 99,81 \\
\hline Amostra & $\mathrm{Sc}$ & $\mathrm{Ba}$ & $\mathrm{Co}$ & $\mathrm{Ga}$ & $\mathrm{Hf}$ & $\mathrm{Nb}$ & $\mathrm{Rb}$ & $\mathrm{Sn}$ & $\mathrm{Sr}$ \\
\hline $149-1$ & 51 & 53,7 & 80,6 & 11,6 & 2,1 & 5,1 & 0,8 & 1 & 458,7 \\
\hline $149-4-1$ & 61 & 48 & 84,4 & 17,8 & 4,2 & 11,6 & 0,9 & 2 & 621,2 \\
\hline $149-4-2$ & 50 & 81,3 & 68,5 & 12,5 & 2,2 & 5,9 & 1 & 1 & 517,7 \\
\hline Amostra & $\mathrm{Ta}$ & $\mathrm{Th}$ & $\mathrm{U}$ & $\mathrm{V}$ & $\mathrm{W}$ & $\mathrm{Zr}$ & $\mathrm{Mo}$ & $\mathrm{Cu}$ & $\mathrm{Pb}$ \\
\hline $149-1$ & 0,6 & 0,1 & 0,1 & 350 & 210,2 & 66,1 & 0,1 & 88,2 & 2,4 \\
\hline $149-4-1$ & 0,7 & 1,1 & 0,3 & 463 & 130,6 & 123,6 & 0,1 & 9,4 & 1,7 \\
\hline $149-4-2$ & 0,5 & 0,3 & 0,3 & 365 & 166,8 & 65,2 & 0,1 & 24 & 1,5 \\
\hline Amostra & $\mathrm{Zn}$ & $\mathrm{As}$ & $\mathrm{La}$ & $\mathrm{Ce}$ & $\mathrm{Pr}$ & $\mathrm{Nd}$ & $\mathrm{Sm}$ & $\mathrm{Eu}$ & $\mathrm{Gd}$ \\
\hline $149-1$ & 23 & 0,5 & 21,4 & 10,6 & 5,02 & 23,3 & 5,2 & 1,78 & 6,64 \\
\hline $149-4-1$ & 8 & 0,5 & 20,7 & 26,3 & 5,96 & 27,3 & 6,5 & 2,3 & 8 \\
\hline $149-4-2$ & 15 & 0,5 & 12,4 & 12 & 3,23 & 15,4 & 4,2 & 1,43 & 4,83 \\
\hline Amostra & $\mathrm{Tb}$ & $\mathrm{Dy}$ & $\mathrm{Ho}$ & $\mathrm{Er}$ & $\mathrm{Tm}$ & $\mathrm{Yb}$ & $\mathrm{Lu}$ & $\mathrm{Y}$ & 54 \\
\hline $149-1$ & 1,21 & 7,05 & 1,45 & 4,47 & 0,6 & 3,86 & 0,54 & 54 & 6,4 \\
\hline $149-4-1$ & 1,53 & 9,28 & 1,98 & 5,5 & 0,81 & 5,5 & 0,82 & 6,51 & 37,2 \\
\hline $149-4-2$ & 0,9 & 5,23 & 1,18 & 3,36 & 0,51 & 3,24 & &
\end{tabular}


evidenciado por teores similares de $\mathrm{Al}_{2} \mathrm{O}_{3}, \mathrm{TiO}_{2}, \mathrm{P}_{2} \mathrm{O}_{5}$ e $\mathrm{FeO}^{\mathrm{T}}$ (Figs. 6E-H). Os valores de $\mathrm{CaO}, \mathrm{SiO}_{2}$ e $\mathrm{Na}_{2} \mathrm{O}$ versus $\mathrm{MgO}$ posicionam essas rochas, quando relacionadas às demais, em campos extremos (Figs. 6A, $\mathrm{C}$ e D), com comportamento incongruente. Isto pode sugerir que o enriquecimento em $\mathrm{CaO}$ e empobrecimento em $\mathrm{Na}_{2} \mathrm{O}$ e $\mathrm{SiO}_{2}$ não se relacionam a processos de fracionamento e metamorfismo mas a processos específicos (rodingitização?).

Pelo comportamento geoquímico similar destes litotipos ultramáficos com o de metamáficas da região, confeccionaram-se diagramas geoquímicos discriminantes para observarem-se seus padrões, à semelhança de Gonçalves \& Figueiredo (1992) e Paciullo (1992, 1997). Observaram-se similaridades geoquímicas entre estes litotipos e basaltos oceâni$\cos , E-M O R B$ e toleítos de arcos (IAT; Figs. 6B-H).

Diagramas que exibem o comportamento de razões $\mathrm{Th} / \mathrm{Yb}$ versus $\mathrm{Ta} / \mathrm{Yb}$ (Fig. 7G; Pearce 1982) posicionam estes litotipos em tendência de rochas com comportamento de trajetória em zona de subducção, ao invés de enriquecimento mantélico ou crustal (fracionamento de líquidos). Os elementos traços e ETR destes litotipos, normalizados a valores
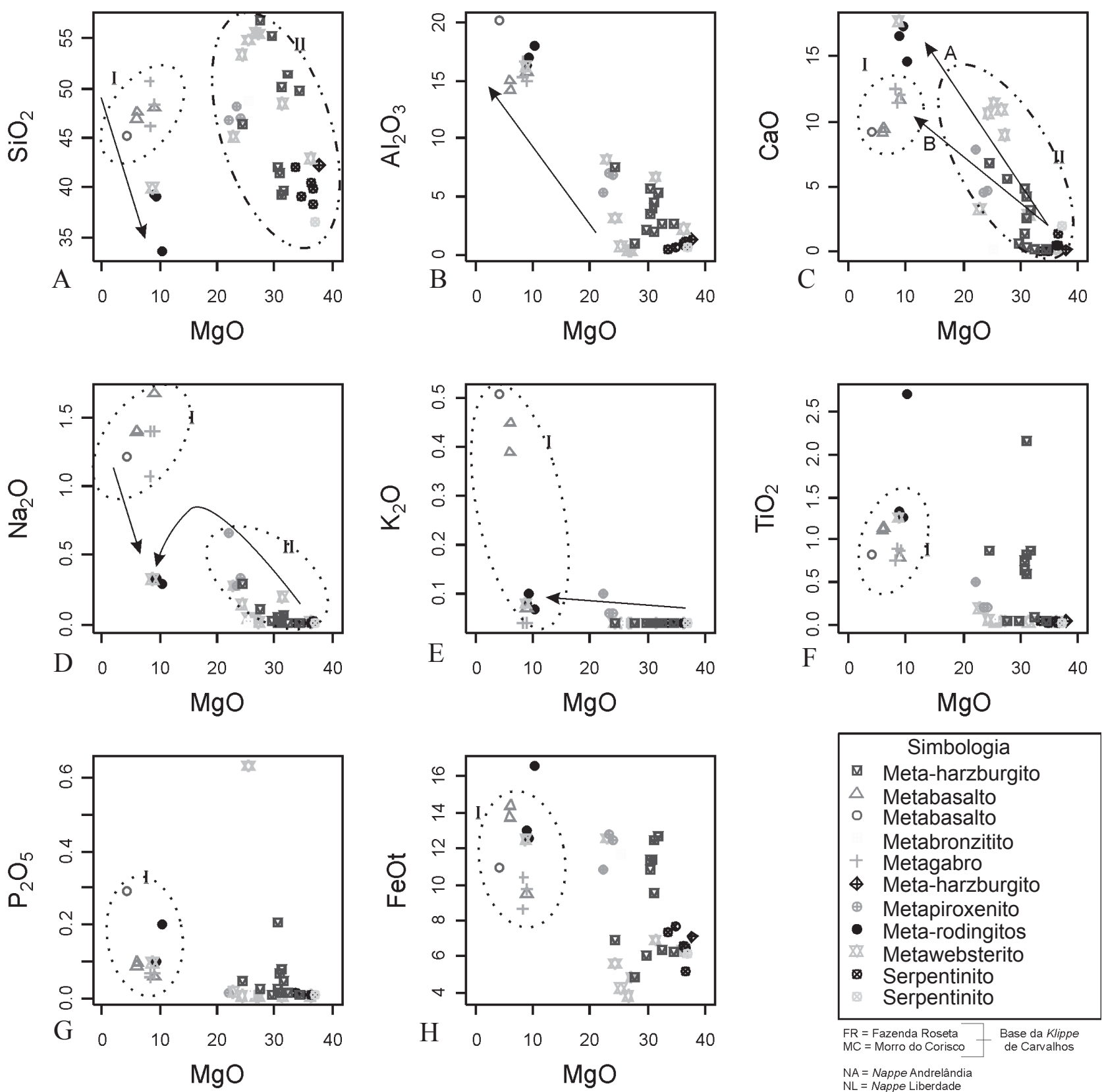

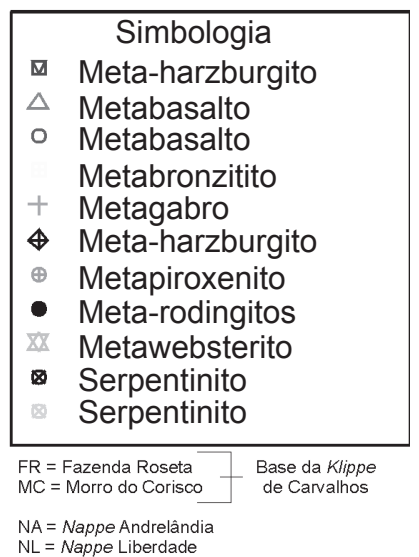

Figura 6 - Diagramas que utilizam o $\mathrm{MgO}$ como índice de diferenciação correlecionando-o com: (A) $\mathrm{SiO}_{2}$; (B) $\mathrm{Al}_{2} \mathrm{O}_{3}$; (C) $\mathrm{CaO}$; (D) $\mathrm{Na}_{2} \mathrm{O}$; (E) $\mathrm{K}_{2} \mathrm{O}$; (F) $\mathrm{TiO}_{2}$; (G) $\mathrm{P}_{2} \mathrm{O}_{5}$ e (H) $\mathrm{FeO}^{T}$ para comparação entre os gnaisses calciossilicáticos (Meta-rodingitos) e outras rochas metaultramáficas (Pinheiro 2008) e metamáficas (Pinheiro inédito) da região de trabalho. Campos: I) metamáficas e II) metaultramáficas. 
de basaltos N-MORB (Saunders et al. 1988), quando comparados com os de rochas metamáficas da região (Figs. 7A e B), mostram assinaturas similares, com padrão côncavo em relação aos elementos incompatíveis, enriquecimento nos large-ion lithophile elements (LILE) e empobrecimento nos high-field strength elements (HFES), fortes anomalias negativas de $\mathrm{Rb}$ e $\mathrm{Nb}$ e anomalias positivas de $\mathrm{Sr}$. Os padrões de ETR destes litotipos mostram padrão "rampa" e anomalia negativa de Ce, de modo similar aos
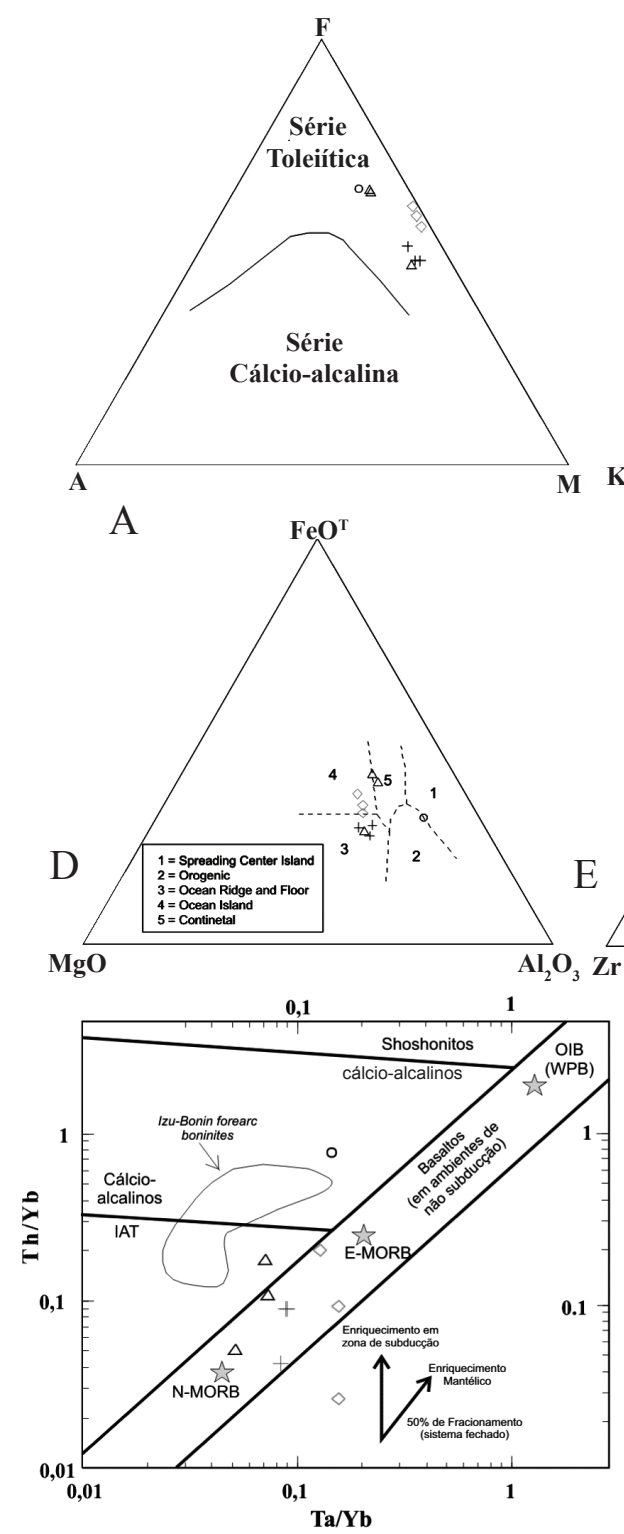

G

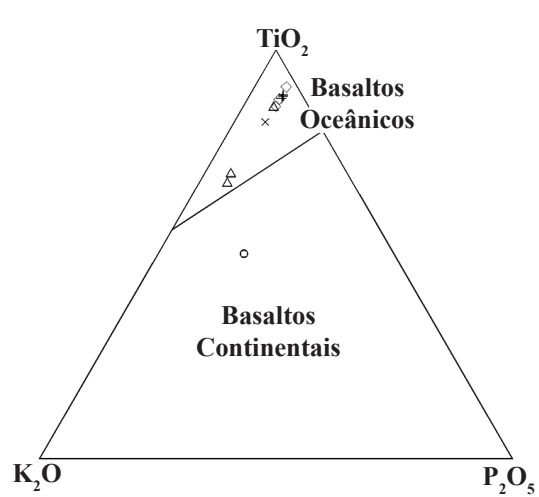

$\mathrm{B}$
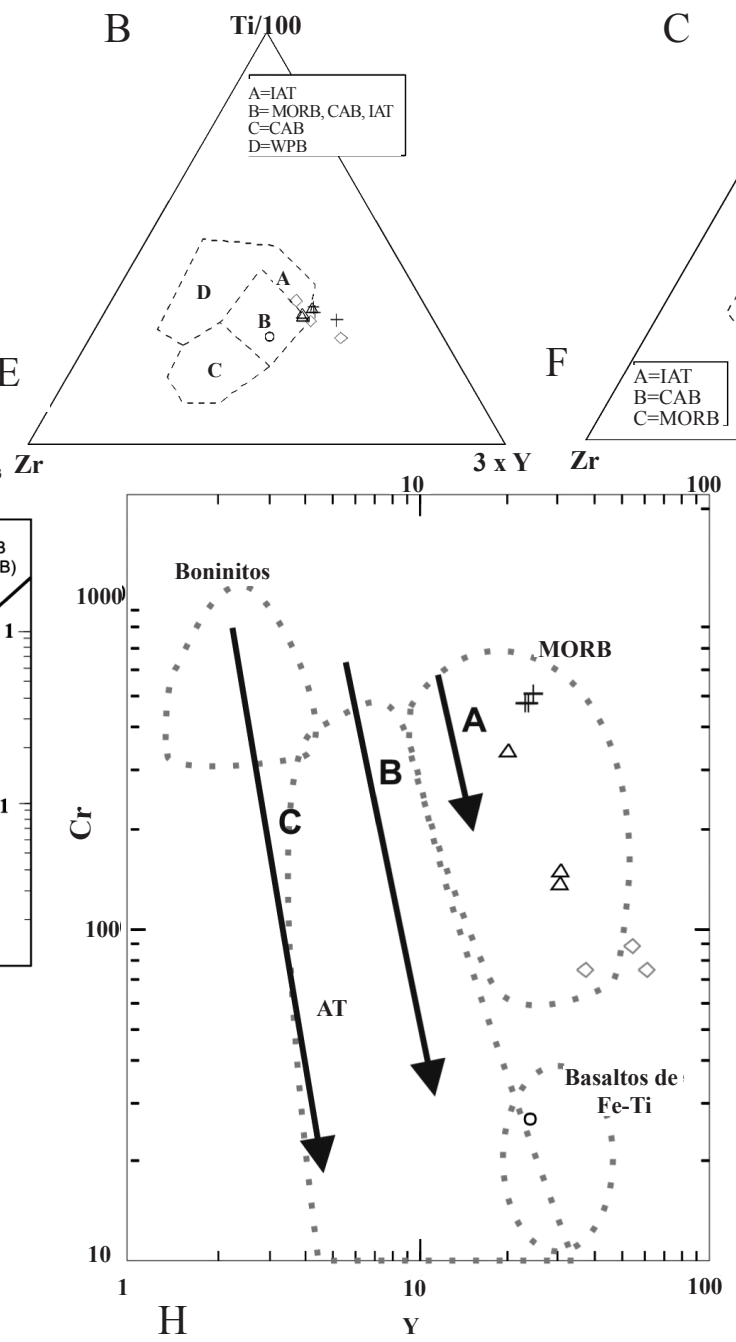

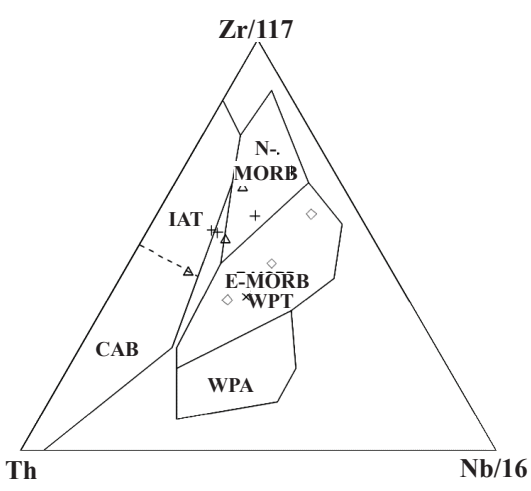

$\mathrm{C}$
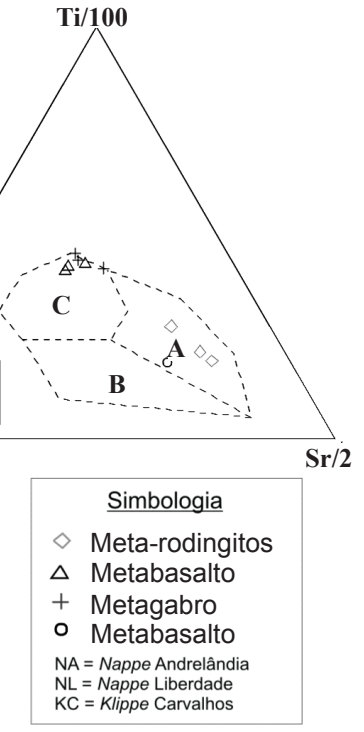

Figura 7 - Diagramas que apresentam campos discriminantes com análises dos gnaisses de composição calciossilicática e de rochas metabásicas da região estudada. Diagramas: (A) AFM (Irvine \& Baragar 1971); (B) $\mathrm{K}_{2} \mathrm{O}$ versus $\mathrm{P}_{2} \mathrm{O}_{5}$ versus $\mathrm{TiO}_{2}$ (Pearce \& Cann 1973); (C) $\mathrm{Zr} / 117$ versus $\mathrm{Th}$ versus $\mathrm{Nb} / 16$ (Wood 1980); (D) $\mathrm{FeO}$ versus $\mathrm{MgO}$ versus $\mathrm{Al}_{2} \mathrm{O}_{3}$ (Meschede 1986); (E) Ti/100 versus $\mathrm{Zr}$ versus $Y^{*} 3$ (Pearce \& Cann 1973); $(F)$ Ti/100 versus $\mathrm{Zr}$ versus Sr/2 (Pearce \& Cann 1973); (G) Th/Yb versus Ta/Yb (Pearce 1982); e (H) Cr versus $Y$ (Pearce 1982). As linhas $A, B$ e $C$ representam o padrão de cristalização para o fracionamento de $\mathrm{Cr}$ espinélio + olivina + piroxênio a partir de magmas de composições MORB, IAT e boniníticas, respectivamente. 
(meta)ultramafitos (Fig. 7D). Estas rochas quando comparadas, pelos elementos normalizados ao condrito, com metaultramáficas da região, exibem comportamento mais similar do que os das metamáficas (Figs. 8A e B), com padrões semelhantes aos LILE, porém anômalos em relação aos HFES, à exceção do metabronzitito que exibe padrões similares.

Em relação aos ETR normalizados (Fig. 8D), é plausível uma associação parental entre essas rochas estudadas e os (meta)ultramafitos adjacentes que exibem padrão de abundância similar.

Evans et al. (1979) apresentaram informações e critérios diagnósticos discriminantes entre eclogitos e metabasaltos toléticos com afinidade de assoalho oceânico (associados a rochas ultramáficas), na associação granada lherzolito, que ocorrem em meio a metassedimentos da nappe Penínica Adula-Cima Lunga, na Suíça. Essas rochas constituem-se de clinopiroxênio e granada e produtos rodingitizados, reequilibrados, posteriormente, em fácies eclogito. Evans et al. (1979) identificaram uma variação contínua na composição química, textural e mineralógica, a partir dos eclogitos $(\mathrm{Jd}>10 \%)$ aos rodingitos $\left(\mathrm{CaO} \approx 24 \%\right.$ e $\left.\mathrm{Na}_{2} \mathrm{O}<0,1 \%\right)$ e atribuíram, ainda, efeito pouco significativo na distribuição dos elementos menores e traços, no processo de rodingitização e em episódios sucessores de alto grau.

A partir dos dados de Evans et al. (1979), de rochas (meta)rodingíticas, eclogitos e de transição
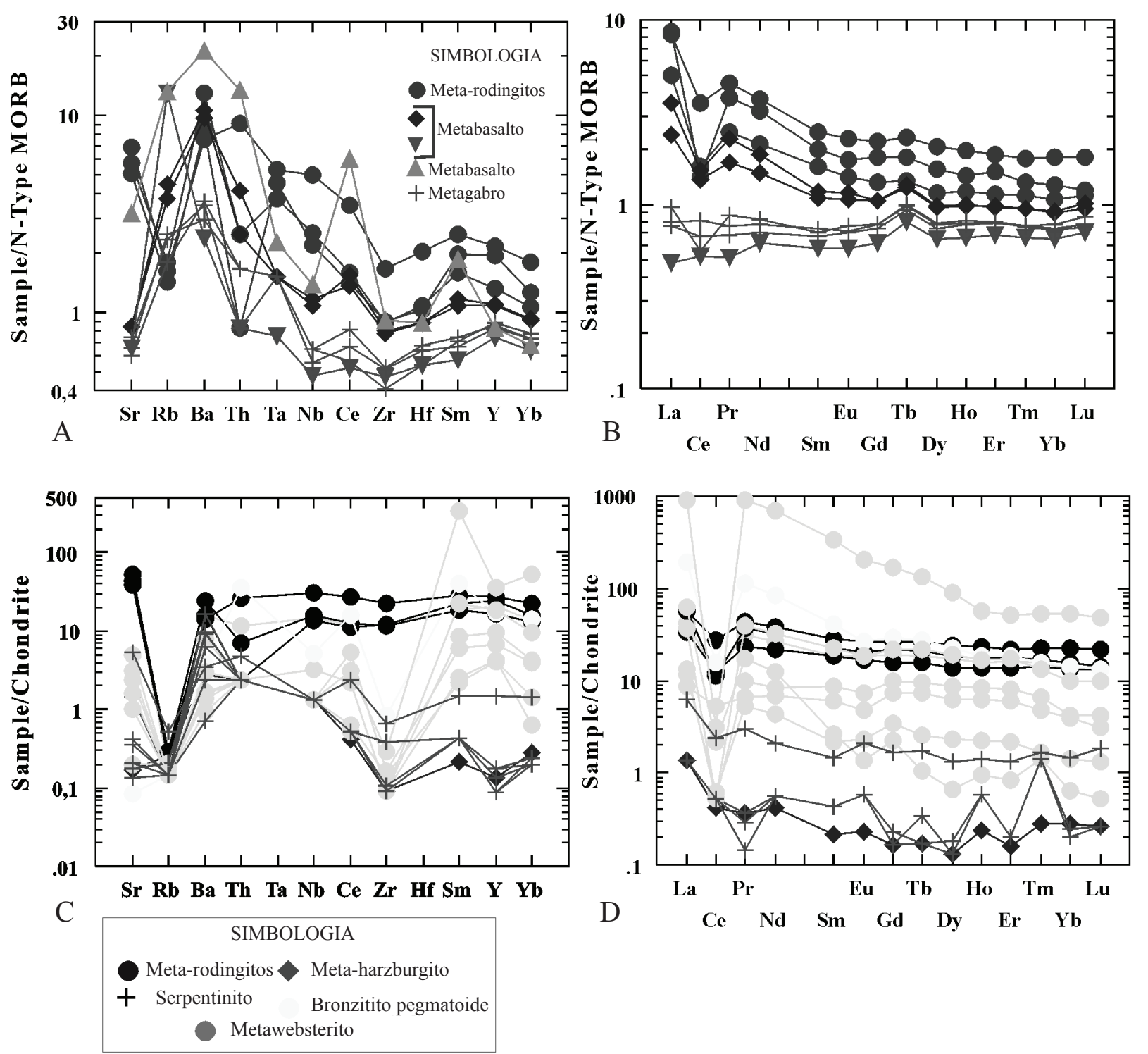

Figura 8 - Diagramas multielementos que mostram valores de elementos incompativeis dos gnaisses de composição calciossilicática comparados com os de rochas da região: (A) padrões de LILE e HFSE comparados aos das metamáficas (valores normalizados para basaltos N-MORB; Saunders et al. (1988); (B) padrões de ETR comparados aos das metamáficas (valores normalizados para basaltos N-MORB; Saunders et al. (1988); (C) padrões de LILE e HFES comparados com os das metaultramáficas e (D) padrões de ETR comparados aos das metaultramáficas. Valores de normalização do condrito de Sun and McDonough (1989). 


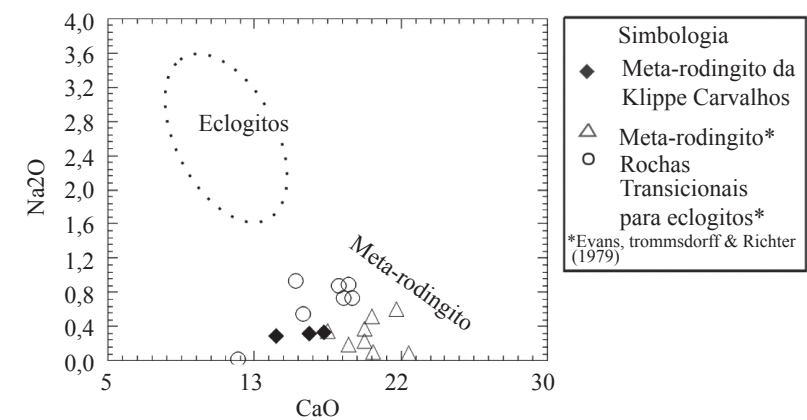

Figura 9 - Diagrama que discrimina eclogitos e Meta-rodingito de Cima di Gagnone, Suiça (Evans et al. 1979) e os granada-clinopiroxênio-hornblenda gnaisses com epídoto (Gn) do corpo da Fazenda da Roseta.

de Cima di Gagnone, Suíça, e comparando-os com os litotipos em questão, observa-se padrão geoquímico similar destes litotipos estudados com os das rochas de transição (Fig. 9).

\section{DISCUSSÃO E CONSIDERAÇÕES FINAIS}

Pelos dados e discusões acima, foram feitas considerações sobre estes gnaisses calciossilicáticos atípicos e suas associações mineralógico-texturais, no ultramafito da Fazenda da Roseta, e suas implicações petrológico-tectônicas. Para discussões finais, consideram-se sobre estes metaultramafitos: 1) modo de ocorrência local e regional, associados a ultramafitos ovóides de pequenas dimensões (serpentinitos, metawebsterito, meta-harzburgito e metabronzitito); 2) presença de eclogitos e lentes do embasamento entre metassedimentos oceânicos, pelágicos a hemiplágicos, em nappes brasilianas; 3) serpentinitos com serpentinização primária; e, 4) aspectos texturais e geoquímicos peculiares dos litotipos estudados.

Assim, interpreta(m)-se essa(s) litologia(s) como resultante(s) do reequilíbrio químio-textural em alto grau, caracterizado pela associação clinopiroxênio + granada + epídoto, de litologia(s), previamente submetida(s) a processo(s) metassomático(s) cálcico(s) a processo(s) de rodingitização, não relacionado(s) a fracionamento magmático e/ou metamórfico, quando comparada(s) a rochas metamáfico-ultramáficas adjacentes da região, parentais, das quais esse(s) litotipo(s), provavelmente, constitua(m) um membro(s).

O contato desses litotipos estudados (com serpentinitos, meta-harzburgito, metawebsterito e metabronzitito), a associação com mineralogia e texturas típicas, o forte enriquecimento em $\mathrm{Ca}$ e litogeoquímica muito diferente, sugere que os mesmos registrem rochas submetidas a processo de enriquecimento em $\mathrm{CaO}$ e a condições metamórficas similares às rochas adjacentes, i.e., rodingitização.

Tais fatos e considerações sugerem que este litotipo constitua membro (meta)rodingítico de fragmentos oceânicos crustais e/ou subcrustais (Pinheiro 2008, Pinheiro \& Suita 2008), submetido ao metassomatismo primário (rodingitização), anterior ao registro metamórfico de maior grau (no mínimo fácies granulito), contemporâneo a arquitetura do Gondwana Ocidental. Esse metamorfismo de alto grau, possivelmente, caracteriza um episódio de colisão dos continentes Paranapanema e São Francisco-Congo num cenário de fechamento do Oceano Brasilíades, que culminou com a incorporação tectônica, em crosta continental, a partir de processos orogenéticos de corpos máficos e/ou ultramáficos, os quais constituem associações do tipo alpino, orogênicas ou ofiolíticas.

\section{AGRADECIMENTOS Os autores agrade-} cem à Fundação de Amparo à Pesquisa do Estado de Minas Gerais (FAPEMIG), Processo CRA1.058/04, pelo financiamento ao projeto, ao Professor Rudolff A. J. Trow (Universidade Federal do Rio de Janeiro), que forneceu inúmeras informações de extrema valia e importância para o desenvolvimento deste trabalho e à Companhia de Pesquisa e Recursos Minerais (CPRM/SGB, SUREG-BH), pelo suporte prestado durante a execução deste trabalho.

\section{Referências}

Alkmim F.F., Marshak S., Fonseca M.A. 2001. Assembling West Gondwana in the Neoproterozoic: clues from the São Francisco craton region, Brazil. Geology, 29: 319-322.

Almeida F.F.M. 1977. O Cráton do São Francisco. Revista Brasileira de Geociências, 7:349-364.

Almeida S. 1992. Petrografia e Geoquímica de rochas ultramáficas na região de Liberdade e Carrancas,
Minas Gerais. Dissertação de Mestrado, Instituto de Geociências, Universidade Federal do Rio de Janeiro, Rio de Janeiro, 166 p.

Almeida S. 1998. Petrologia de rochas ultramáficas associadas ao Grupo Andrelândia e seu embasamento, na região de Liberdade, Arantina, Andrelândia, São Vicente de Minas e Carrancas, $M G$. Tese de Doutorado, Instituto de Geociências, Universidade de São Paulo, São Paulo, 194 p. 
Barnes I. \& O’Neil J.R. 1969. The relationship between fluids in some fresh alpine-type ultramafics and possible modern serpentinization, Western United States. Geological Society of America Bulletin, 80:1947-1960.

Barnes R.J.B. \& O’Neil J.R. 1972. Metamorphic assemblage and the direction of flow of metamorphic fluids in four instances of serpentinization. Contributions to Mineralogy and Petrology, 35:24-36.

Brito Neves B.B. 1999. América do Sul: quatro fusões, quatro fissões e o processo acrescionário andino. Revista Brasileira de Geociências, 29:379-392.

Campos Neto M.C. \& Caby R. 1999. Neoproterozoic highpressure metamorfism and tectonic constraints from the nappe system south of the São Francisco Craton, Southeast Brazil. Precambrian Research, 97:3-26.

Campos Neto M.C. \& Caby R. 2000. Terrane accretion and upward extrusion of high-pressure granulites in the neoproterozoic nappes of Southeast Brazil: petrologic and structural constraints. Tectonics, 19:669-687.

Campos Neto M.C. 2000. Orogenic systems from Southwestern Gondwana: an approach to BrasilianoPan African cycle and orogenic collage in southeastern Brazil. In: Cordani U.G., Milani E.J., Thomaz Filho A., Campos D.A. (ed.). 2000. Tectonic Evolution of South America. Rio de Janeiro, p. 335-365.

Campos Neto M.C., Basei M.A.S., Vlach S.R.F., Caby R., Szabó G.A.J., Vasconcelos P. 2004. Migração de orógenos e superposição de orogêneses: um esboço da colagem brasiliana no sul do Cráton do São Francisco, SE - Brasil. Geologia USP, Sér. cient, 4:13-40.

Campos Neto M.C., Janasi V.A., Basei M.A.S., Siga Jr. O. 2007. O. Sistema de nappes Andrelândia, setor oriental: litoestratigrafia e posição estratigráfica. Revista Brasileira de Geociências, 37(4):47-60.

Cioffi C.R. 2009. Geologia dos granulitos de alta pressão da klippe Carvalhos, extensão sul da Faixa Brasília. Dissertação de Mestrado, Instituto de Geociências, Universidade de São Paulo, São Paulo, 104 p.

Coleman R.G. 1963. Serpentinites, rodingites, and tectonic inclusions in Alpine-type mountain chains. Geological Society of America, 73:130.

Coleman R.G. 1967. Low temperature reaction zones and alpine ultramafic rocks of California, Oregon, and Washington. U.S. Geological Survey Bulletin, 1247:1-49.

Coleman R.G. 1977. Ophiolites - Ancient oceanic lithosphere? In: Minerals and Rocks, 12. ed. P.J. Wyllie, Berlin, Germany, Springer-Verlag. 229 p.

Dardenne M.A. 2000. The Brasília fold belt. In: Cordani U.G., Milani E.J., Thomaz-Filho A., Campos D.A. (eds.). Tectonic Evolution of South America, $31^{\text {th }}$ Int. Geol. Congr., Rio de Janeiro, p. 231-263.

Evans B.W., Trommsdorff V., Richter W. 1979. Petrology of a eclogite-metarodingite suite at Cima di Gagnone, Ticino, Switzerland. American Mineralogist, 64:15-31.

Frost B.R. 1975. Contact metamorphism of serpentinite, chloritic blackwall and rodingite at Paddy-Go-Easy Pass, Central Cascades, Washington. Journal of Petrology, 16(2):272-313.
Frost B.R. \& Beard J. S. 2007. On silica activity and serpentinization. Journal of Petrology, 48:1351-1368.

Fuck R.A., Jardim de Sá E.F., Pimentel M.M., Dardenne M.A., Pedrosa-Soares A.C. 1993. As Faixas de Dobramentos Marginais do Cráton do São Francisco. In: Dominguez J. \& Misi A. (coords.) O Cráton do São Francisco. SBG, Salvador (BA), Anais, p. 161-185.

Gonçalves M.L. \& Figueiredo M.C.H. 1992. Geoquímica dos anfibolitos de Santana do Garambéu (MG): implicações sobre a evolução do Grupo Andrelândia. Geochimica Brasiliensis, 6:127-140.

Hasui Y. \& Oliveira M.A.F. 1982. Província Mantiqueira. In: Almeida F.F. \& Hasui Y. (eds.). O Pré-cambriano do Brasil. Edgar Blücher, p. 308-344.

Heilbron M., Valeriano C.M., Valladares C.S., Machado N. 1995. A Orogênese Brasiliana no segmento central da Faixa Ribeira, Brasil. Revista Brasileira de Geociências, 25:249-266.

Heilbron M., Duarte B.P., Valladares C.S., Nogueira J.R., Tupinambá M., Silva L.G.E. 2003a. Síntese geológica regional do bloco oriental (Zona da Mata). In: PedrosaSoares A.C., Noce C.M., Trouw R.A.J., Heilbron M. (eds.). Projeto Sul de Minas. Universidade Federal de Minas Gerais, Belo Horizonte (MG), p. 8-50.

Heilbron M., Tupinambá M., Junho M.C.B., Pentagna F.V.P., Trouw R.A., Valeriano C.M., Toledo C., Medeiros R.M., Roig H.L. 2003b. Mapa Geológico Santa Rita do Jacutinga. In: Pedrosa-Soares A.C., Noce C.M., Trouw R.A.J., Heilbron M. (eds.). Projeto Sul de Minas. Universidade Federal de Minas Gerais, Belo Horizonte (MG), Companhia Mineradora de Minas Gerais - COMIG.

Irvine T.N. \& Baragar W.R.A. 1971. A guide to the chemical classification of the common volcanic rocks. Canadian Journal of Earth Sciences, 8:523-548.

Janoušek V., Farrow C.M., Erban V. 2006. Interpretation of whole-rock geochemical data in igneous geochemistry: introducing Geochemical Data Toolkit (GCDkit). Journal of Petrology, 47(6):1255-1259.

Meschede M. 1986. A method of discriminating between different types of mid-ocean ridge basalts and continental tholeiites with the $\mathrm{Nb}-\mathrm{Zr}-\mathrm{Y}$ diagram. Chemical Geology, 16:207-218.

Motta R.G., Moraes R., Trouw R.A.J., Campos Neto M.C.C. 2010. Reconstrução e comparação de trajetórias P-T no sistema de nappes Andrelândia, sul da Faixa Brasília, MG. Geologia USP, Sér. cient. 10(3):79-96.

Paciullo F.V.P. 1992. Orto-anfibolitos no ciclo deposicional Andrelândia: composição química e ambiente tectônico. In: SBG, Congresso Brasileiro de Geologia, 37, São Paulo (SP), Resumos, 2:28-29.

Paciullo F.V.P. 1997. A seqüência deposicional Andrelândia. Tese de Doutorado, Instituto de Geociências, Universidade Federal do Rio de Janeiro., Rio de Janeiro, 263 p.

Paciullo F.V.P., Ribeiro A., Trouw R.A.J. 2003a. Geologia da Folha Andrelândia 1: 100.000. In: Pedrosa-Soares A.C., Noce C.M., Trouw R.A.J., Heilbron M. (org.). 
Geologia e recursos minerais do sudeste mineiro, Projeto Sul de Minas - Etapa I (COMIG, UFMG, UFRJ, UERJ), Relatório Final, Belo Horizonte (MG), Companhia Mineradora de Minas Gerais - COMIG, I:84-119.

Paciullo F.V.P., Trouw R.A.J., Ribeiro A., Simões L.A., Lopes M. 2003b. Mapa Geológico - Folha Andrelândia 1: 100.000. In: Pedrosa-Soares A.C., Noce C.M., Trouw R.A.J., Heilbron M. (org.). Geologia e recursos minerais do sudeste mineiro, Projeto Sul de MinasEtapa I (COMIG, UFMG, UFRJ, UERJ), Relatório Final. Belo Horizonte (MG): Companhia Mineradora de Minas Gerais - COMIG.

Pearce J.A., Cann J.R. 1973. Tectonic setting of basic volcanic rocks determined using trace element analyses. Earth and Planetary Science. Letters, 19:290-300.

Pearce J.A. 1982. Trace element characteristics of lavas from destructive plate boundaries. In: Thorpe R.S. (ed.) Andesites, p. 525-548, John Willey and Sons, Chichester, U.K.

Pimentel M.M., Fuck R.A., Botelho N.F. 1999. Granites and the geodynamic history of the neoproterozoic Brasilia Belt, Central Brazil: a review. Lithos, 46(3):1-21.

Pimentel M.M., Fuck R.A., Jost H., Ferreira-Filho C.F., Araújo S.M. 2000. The basement of the Brasillia Belt and the Goiás magmatic arc. In: Cordani U.G., Milani E.J., Thomaz-Filho A., Campos D.A. (eds.). Tectonic Evolution of South America, $31^{\text {st }}$ International Geological Congress, Rio de Janeiro, p. 195-229.

Pinheiro M.A.P. 2008. Geologia e petrologia de rochas ultramáficas neoproterozóicas da Folha Andrelândia, borda sul do Cráton São Francisco, Minas Gerais. Dissertação de Mestrado, Universidade Federal de Ouro Preto, 170 p.

Pinheiro M.A.P. \& Suita M.T.F. 2008. Metamorfismo de fundo oceânico e de alto grau em meta-peridotitos ofiolíticos neoproterozóicos, Faixa Brasília Sul, Minas Gerais. Revista Brasileira de Geociências, 38(4): 686-699.

Ribeiro A., Andreis R.R., Trouw R.A.J., Paciullo F.V.P., Valença J.G. 1995. Evolução das bacias proterozóicas e o termo-tectonismo brasiliano na margem sul do cráton do São Francisco. Revista Brasileira de Geociências, 25(4):235-248.

Ribeiro A., Paciullo F.V.P., Trouw R.A.J., Valença J.G. 2003a. Síntese geológica regional do Bloco Ocidental, Campos das Vertentes e Sul de Minas. In: PedrosaSoares A.C., Noce C.M., Trouw R.A.J., Heilbron M. (orgs.). Geologia e Recursos Minerais do Sudeste Mineiro. Projeto Sul de Minas Etapa I (COMIG, UFMG, UFRJ, UERJ), Relatório Final, Belo Horizonte (MG): COMIG, 1:51-152.

Ribeiro A., Ávila C.A., Valença J.G., Paciullo F.V.P., Trouw R.A.J. 2003b. Geologia da Folha São João del Rei (1:100.000). In: Pedrosa-Soares A.C., Noce C.M., Trouw R.A.J., Heilbron M. (orgs.). Geologia e recursos minerais do sudeste mineiro, Projeto Sul de Minas- Etapa I (COMIG, UFMG, UFRJ, UERJ), Relatório Final., Belo Horizonte (MG): Companhia Mineradora de Minas - COMIG, 2:521-659.

Rice J.M. 1983. Metamorphism of rodingites. I. Phase relations in a portion of the system $\mathrm{Ca} 0-\mathrm{MgO}-\mathrm{Al}_{2} \mathrm{O}_{3}$ $\mathrm{SiO}_{2}-\mathrm{CO}_{2}-\mathrm{H}_{2} \mathrm{O}$. American Journal of Science, 283-A: 121-150.

Richard L.R. 1995. Mineralogical and petrological data processing system for Windows, version 2.02. Minpet Geological Software-Logiciel Géologique Minpet, Quebec.

Santos L.C.S. 1972. Evolução geoquímica e mineralógica de um solo niquelífero. Dissertação de Mestrado, Instituto de Geologia, Universidade Federal do Rio de Janeiro, 105 p.

Saunder A.D., Norry M.J., Tarney J. 1988. Origin of MORB and chemically derived mantle reservoirs: trace elements constraints. Journal of Petrology, Special volume (1):415-445.

Silva, R.R. 1992. Estratigrafia, metamorfismo e geologia estrutural do Grupo Andrelândia em Carvalhos, sul de Minas Gerais. Dissertação de Mestrado, Departamento de Geologia, Universidade Federal do Rio de Janeiro; pp.

Sun S.S. \& McDonough W.F. 1989. Chemical and isotopic systematics of oceanic basalts: implications for mantle composition and processes. In: Saunders A.D. \& Norry M.J. (eds.) Magmatism in the Ocean Basins. Geological Society Special Publication, London, 42:313-345.

Trouw R.A.J. 1992. Evolução tectônica ao sul do Cráton do São Francisco baseada em análise metamórfica. In: Congresso Brasileiro de Geologia, 37, Anais, p. 327.

Trouw R.A.J., Pankhrust R. J. 1993. Idades radiométricas ao sul do Cráton do São Francisco: região da Folha Barbacena, Minas Gerais. In: Simpósio do Cráton do São Francisco, Salvador, Anais, 2:260-262.

Trouw R.A.J., Heilbron M., Ribeiro A., Paciullo F.V.P., Valeriano C.M., Almeida J.C., Tupinambá M., Andreis R.R. 2000. The central segment of the Ribeira Belt In: Cordani U.G., Milani E.J., Thomaz Filho A., Campos D.A. (eds.). Tectonic Evolution of South America, $31^{\text {st }}$ International Geological Congress, Rio de Janeiro, p. 287-310.

Wares R.P., Martin R.F. 1980. Rodingitization of granite and serpentinite in the Jeffrey mine, Asbestos, Quebec. Canadian Mineralogist, 18:231-240.

Whitney D.L., Evans B.W. 2010. Abreviations for names of rock-forming minerals. American Mineralogist, 95:185-187.

Wood D.A. 1980. The application of a Th-Hf-Ta diagram to problems of tectonomagmatic classification and to establishing the nature of crustal contamination of basaltic lavas of the British Tertiary volcanic province. Earth Planet Science Letters, 50:11-30.

Manuscrito ID 20828

Recebido em: 17/02/2011

Aprovado em: 23/04/2012 